\title{
Teachers' Perceptions of Using Health Disparities Content to Engage High Schoolers in Urban Communities
}

\author{
Megha Ramaswamy', Crystal Lumpkins', Maria Alonso Luaces', Karin Chang², and Paula Cupertino ${ }^{3}$
}

${ }^{1}$ University of Kansas School of Medicine; ' $U$ niversity of Kansas; ${ }^{3}$ Hackensack University Medical Center

Keywords: Health Disparities, Professional Development, High School

Publication Date: June 21, 2019

DOI: https://doi.org/10.15695/jstem/v2i1.11

\begin{abstract}
The objective of this study was to report on teachers' perceptions of using health disparities content to engage high school students in urban communities over the course of a summer health disparities professional development (PD) program. Teachers participated in a three-week, 80-hour summer PD, where they received content on health disparities, met with health disparities researchers, and developed project-based learning units focused on health disparities. To understand teachers' perceptions of integrating health disparities content in the classroom, thematic coding was used to analyze data from focus groups collected before and after summer PD for three cohorts of high school teachers in two urban school districts (2016-2018, N=22 teachers). Findings were that: 1) Teachers showed awareness of the social challenges students face, even prior to starting a summer PD on health disparities; 2) Teachers appreciated the role of community engagement and student activism as a solution to health disparities and felt that they would be able to engage students with this material; 3) Teachers needed resources, mostly in the form of community connections, to fully integrate health disparities lessons, with community engagement infused throughout. Findings suggest that teachers are prepared to integrate information about community context in their classes and could be furthered empowered to teach about health disparities with the right community connections and engagement infrastructure.
\end{abstract}

\section{INTRODUCTION}

A summer health disparities professional development (PD) program for high school teachers in Kansas City, Kansas and Wichita, Kansas was developed, with the premise that if teachers were empowered to teach content that resonates with students' real world community concerns, then those students would be more motivated to pursue STEM solutions to local problems (Alonso Luaces et al., 2018). Prior to implementation of the summer health disparities PD, our study sought to understand whether teachers were in touch with students' realities, that is the social, political, historic, and economic contexts of students' lives, as a baseline for their preparation in teaching about these realities. From a programmatic standpoint, the study reported on teachers' overall perceptions of using health disparities content to engage high school students in urban communities.

Health disparities refer to differences in morbidity, mortality, and shorter life expectancy for some groups - for example racial and ethnic minorities or those from lower socio- economic status - relative to groups that do not share those characteristics (U.S. Institute of Medicine, 2006). Over the last two decades scientists have sought to better understand differences in health outcomes, by using research methods that engage community members, health care providers, and policy makers. Health disparities research has focused on socioecological factors that put some groups at risk of health outcomes, compared to other groups. The summer health disparities PD focused on empowering teachers to engage high school students as experts of their own communities as a pedagogical tool.

Emphasis on students' realities is mirrored in current national trends in education reform. In 2013, the Kansas State Board of Education adopted the Next Generation Science Standards (NGSS) as the Kansas College and Career Ready Standards for science (Kansas State Department of Education, 2019). The NGSS were developed as a response to alarming data on K-12 students' performance in STEM as 
well as to replace facts-based teaching with content focused on exploration of real-world phenomena (Krajcik et al., 2014 and 2015; National Research Council, 2013). The state Department of Education (Kansas) joined this movement and is currently working with each district in the state to revamp K-12 curricula and transform the health science pathway.

To date, there is scant literature about teaching health disparities in the high school setting. Health disparities training has been effectively integrated in undergraduate, graduate public health, and medical school context (Anderson et al., 2011; Florence and Behringer, 2011; Jacquez and Ghantous, 2013; Smith et al., 2007). The literature has demonstrated that community-university partnerships, service-learning, and experiential activities are critical in successful programming. Other researchers have also effectively engaged with high school students directly to address health disparities (Siciliano et al., 2018; Sprague Martinez et al., 2016). While there are curricula available for high school teachers to use to integrate health disparities content in their teaching, these curricula have not been evaluated in the peer-reviewed literature (Teaching Tolerance, 2019; University of Maryland, 2018).

There is a long history of effective PD programs based on training high school teachers in university and industry partner labs (Storm and Lichenstein, 2019), so it would stand to reason that a teacher-researcher health disparities PD would translate to similar results. These teacher-researcher PD programs have changed teaching practice - helping teachers incorporate more hands-on and student-centered activities, and developing projects more aligned with real-life situations (Pop et al., 2010). A recent longitudinal study of teacher-researcher PD also showed that such programming can increase teacher retention and willingness to try new things in the classroom to better reach students (Storm and Lichenstein, 2019). Teachers believe that teacher-researcher PD programs can translate to better experiences for their students.

A literature on culturally responsive teaching has also suggested that if teachers are to be prepared to engage students effectively, they have to practice "sociocultural consciousness," that is awareness of students' realities - about their communities and social position in relation to race, ethnicity, class, and gender (Villegas and Lucas, 2002). To be most effective, teachers have to see it as their responsibility to bring about change and make conditions more equitable for students (Villegas and Lucas, 2002).

Thus, this study focused on teachers' perceptions of using health disparities content to engage high school students in urban communities over the course of a summer health disparities PD. Specifically, the study focused on teachers' knowledge of the health disparities issues students face, as a measure of sociocultural consciousness; their own knowledge and attitudes about health disparities content; percep- tions of how the material might resonate with students; and what barriers the teachers would face to engaging students with health disparities content. The goal of this study was to show how teachers evolve as a group over the course of PD, including an articulation of their knowledge and attitudes about health disparities, and perceived barriers to successful integration of health disparities content in the classroom. A greater understanding of these factors would provide important information for development and evaluation of such programming.

\section{METHODS}

Study design. This study employed a pre-post focus group design over the course of a summer health disparities PD to characterize teachers' perceptions of using health disparities content to engage high school students in urban communities. The pre-post design was chosen because of interest in changes in the way teachers talked about issues - particularly knowledge and attitudes about health disparities. But the study also sought to capture overall teacher perceptions of integrating health disparities content for the classroom over the course of the PD. This focus group study was designed to show how teachers evolved as a group over the course of PD, which is more fitting for use of a qualitative method (narrative focused) compared to a quantitative method (Basch, 1987). Focus groups, as a qualitative method, were used to better understand the context in which teachers work together to make meaning and reflect their own and each other's experience in the classroom (Hollander, 2004). This is only one evaluation component of the overall PD, focusing specifically on teachers' perceptions of using health disparities content in their urban classrooms over the course of a summer health disparities PD.

Program Description. At the start of the Teachers and Students for Community-Oriented Research and Education (TSCORE) summer health disparities PD, administrators from Kansas City and Wichita school districts partnered with health disparities researchers, curriculum specialists, and state educational support services to facilitate PD for high school teachers in urban communities (Alonso Luaces, 2018). During summer PD, partners worked collaboratively with teachers to develop health disparities content rooted in local community problems. A partnership with university health disparities researchers was designed to provide teachers with exposure to real community health projects and demonstrate how such community connections could be used in high school health sciences classrooms. The idea was that integration of these community-based projects into the classroom would bridge the gap between what students learned in high school and what was occurring in their communities. The partnerships would also create a profession- 
al network through which the teachers could connect with community researchers for resources - guest speakers, tours, supplies, and feedback.

The summer health disparities PD lasted on average threeweeks for 80 hours total. The summer PD was made available by health disparities researchers, educational specialists, and community members. The PD included information on health disparities content, health careers, and guidance on developing project-based learning units focused on health disparities. The three-week PD is described in Table 1, and the curriculum described in detail elsewhere (Alonso Luaces, 2018). Briefly, the PD included the following components: 1) Using a pedagogy of questioning, TSCORE staff engaged teachers in thinking critically about the definition and causes of health disparities; 2) Using local case studies presented by community researchers, the PD provided exposure to potential topics for unit development and community research. Teachers were also given the opportunity to question researchers about methods of evaluation, in order to think about evaluation as part of their own unit development process; 3 ) Teachers were able to explore alternative methods of data collection that might work in a high school context, including for example exposure to photovoice, eth- nographic methods, and interviews with stakeholders; 4) Teachers were able to expand their social networks to enhance unit development with one-on-one sessions with pedagogical and content experts. The meetings were designed so that teachers could get feedback and share ideas.

Teacher recruitment and participants. Teachers were recruited into the TSCORE program by the TSCORE leadership team, made up of a health disparities researcher (PI), an educational evaluation expert (Co-PI), and other TSCORE staff (including a former high school educator and current project director). The TSCORE leadership team worked with each district's Career Technical Education coordinator to identify potential applicants. TSCORE staff reviewed teachers' applications and conducted a brief telephone brief to assess their interest in participating in the program. High school teachers were invited to participate, with special focus in reaching out to teachers involved in the health sciences career pathway.

Twenty-two teachers participated in TSCORE, representing five public high schools in Kansas City and Wichita, Kansas (see Table 2 for participation over the three years of implementation). For participation in the three-week

Table 1. Health Disparities Content for Summer Professional Development

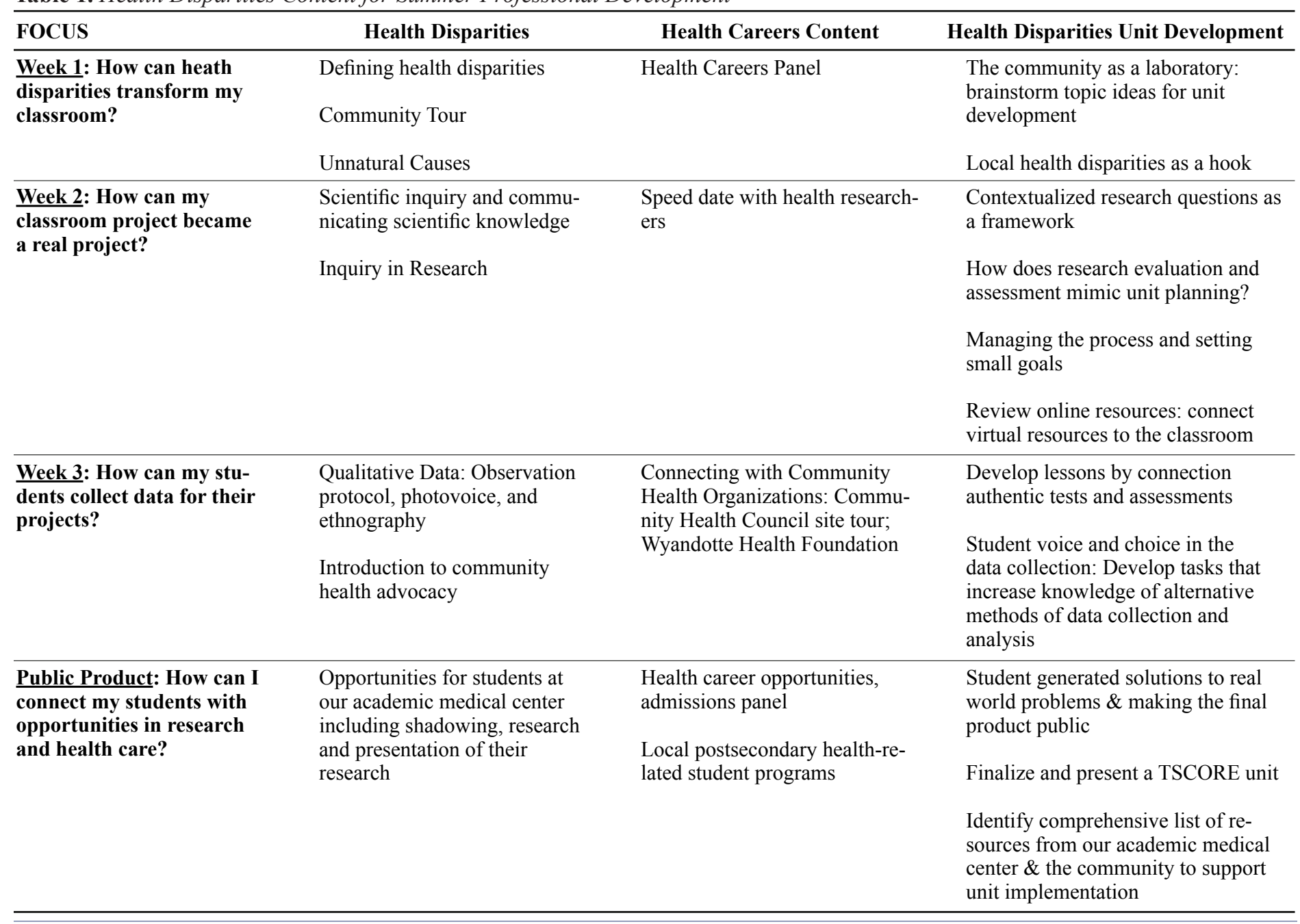


summer health disparities PD, teachers were paid a stipend of $\$ 3,000$ to compensate for summer salary. Though new teachers were recruited every year, returning teachers were invited to come back for PD as peer teaching fellows, with a smaller stipend of $\$ 1,500$ and shorter time commitment. Data from returning teachers were excluded from this focus group study.

In 2016, TSCORE was only implemented in Kansas City, so there was one pre-and one post-PD focus group ( $\mathrm{N}=2$ focus groups; 5 teachers participated). In 2017, TSCORE was in place in both Kansas City and Wichita, so there was one pre-and one post-PD focus group in each city ( $\mathrm{N}=4$ focus groups; 5 teachers participated in Kansas City and 5 participated in Wichita). In 2018, TSCORE was still in place in both Kansas City and Wichita, so there was one pre-and one post-PD focus group in each city ( $\mathrm{N}=4$ focus groups; 5 teachers participated in Kansas City and 2 participated in Wichita). Over the course of the three years, a total of 10 focus groups were conducted (five pre-and five post-PD focus groups) with 22 teachers total.

Data collection. The principal author designed the focus group prompts based on domains from the critical health literacy literature (knowledge, attitudes, intentions for teaching health disparities content, and opportunities for civic engagement) (Nutbeam, 2000). Critical health literacy is defined as having skills oriented towards individual, social, and political action (Nutbeam, 2000), which was fitting given the focus on empowering teachers to engage their students in social change. For knowledge, teachers were asked to define health disparities, and to give examples of what health disparities look like in their own and in students' communities. For attitudes, teachers were asked to give examples of issues they thought caused health disparities, as well as how they thought health disparities might affect the students they teach. For intention, teachers were asked how they might incorporate health disparities content into their units; what impact they felt the material would have on students' critical consciousness; and what barriers they faced for implementation. For civic engagement, teachers were asked how they planned to engage students in community action or if they had experience with doing so in the past. All prompts are listed in Table 3. Though prompts were operationalized using a critical health literacy framework, content ultimately reflected teachers' perceptions of what was going on with students and what they felt would transpire in the classroom.

Each focus group lasted approximately one hour. Focus groups were administered by the principal author or trained research staff. The data collection protocol, all aspects of study involvement, and teacher consent procedures were approved by the university's Institutional Review Board.

Data management and analysis. All focus groups were audio-recorded, transcribed by TSCORE research assistants, and uploaded into Dedoose software for management and analysis. Data were analyzed using a five-step process (Ulin et al., 2005): 1) The principal author developed a preliminary code list based on focus group prompts/area of investigation into pre- and post- knowledge, attitudes, and intentions for teaching about health disparities; 2) Transcripts were coded in Dedoose or by hand, with additional codes developed as needed through an open-coding process by principal author or a focus group moderator; 3) Dominant themes were extracted from coded data and focus groups, that were driven by area of investigation of pre- and post- knowledge, attitudes, and intentions for teaching about health disparities (see Table 4 for list of codes organized by theme); 4) Representative quotes for each theme were aggregated according to thematic area by the principal author; 5) Any disagreements about themes or representative quotes were resolved through discussion with the team of authors.

\section{RESULTS}

Twenty-two teachers participated in TSCORE. Seventeen were female, five were male, 15 were White, four were Black, one was Asian, one identified as American Indian, and one identified as Latinx. Teachers recruited taught a range of subjects in the Health Sciences Pathway, for example in sociology, human growth and development, and both lower and upper level health science courses. Teachers in Wichita only taught using a pre-packaged Project Lead the

Table 2. TSCORE Participants

\begin{tabular}{lcc}
\hline Year 1 (2016-2017) & Year 2 (2017-2018) & Year 3 (2018-2019) \\
\hline Kansas City & Kansas City & Kansas City \\
5 new teachers & 5 new teachers & 5 new teachers \\
& 3 returning teachers & 3 returning teachers \\
\hline & Wichita & Wichita \\
\hline
\end{tabular}

Total new teachers, $n=22$

Focus group data from returning teachers have been excluded from this study.

Journal of STEM Outreach 
Table 3. Focus Group Prompts

\section{PRE-PD}

1. Knowledge: How do you define health disparities. "Let's go around the room, what is your definition of health disparities? Give examples if you have them."

- Tell me about what the health disparities look like in the community that you teach.

- Tell me about the health context in which your students live. - Individual level: what are your own personal experiences with health inequality. (i.e. personal, volunteer work, seen, heard, know about)

2. Attitudes/Causes: (Health disparities refer to differences in the health status of different groups of people. Some groups of people have higher rates of certain diseases, and more deaths and suffering from them, compared to others. These groups may be based on. Race. Ethnicity.) Given the definition of health disparities, what do you think causes health disparities?

3. Empowerment for Skill/Intention: How have you incorporated health disparities knowledge into your classes?

- How do these activities address health disparities?

- If you have implemented such activities, how did your students react?

- Critical Consciousness: What do you think would have intensified their reaction? What do you think are your limitations in teaching health disparities?

4. Civic Engagement: Have you seen or heard of effective ways to address health disparities?

\section{POST-PD}

1. Knowledge: Give me examples of how your definition of health disparities changed since you completed this PD?

- How has this PD added to your understanding about the health context in which your students live, if at all?

-What tools has the PD given you to address the differences, similarities, and overarching social groups in which your students live, learn, and socialize?

2. Attitudes: What are the causes of health disparities?

3. Empowerment for Skill/Intention: In the units you developed during the PD, how did you incorporate health disparities knowledge into your classes?

- How do these activities address health disparities?

- How do you think your students will react to these activities?

Critical Consciousness: What do you think will intensify their reaction? What other resources do you still need to intensify the experience of your students?

- How confident are you in your ability to teach about health disparities, identify the resources you need, provide them to your students, and engage them in community work to address health disparities?

\section{Civic Engagement:}

-What methods will you utilize so that your students can play an active role in addressing health disparities?

- In the units you developed, how have you incorporated opportunities for students to participate in civic engagement?

Table 4. Code List Organized by Theme

\begin{tabular}{|c|c|c|c|c|}
\hline \multicolumn{5}{|c|}{ Themes } \\
\hline $\begin{array}{l}\text { Knowledge about students' } \\
\text { social context prior to pro- } \\
\text { fessional development }\end{array}$ & $\begin{array}{l}\text { Changing definitions and } \\
\text { attitudes about health } \\
\text { disparities }\end{array}$ & $\begin{array}{l}\text { Perception of impact on } \\
\text { students before profes- } \\
\text { sional development }\end{array}$ & $\begin{array}{l}\text { Plans for integration of } \\
\text { health disparities content } \\
\text { into units }\end{array}$ & $\begin{array}{l}\text { Resources need to be } \\
\text { successful }\end{array}$ \\
\hline \multicolumn{5}{|c|}{ Codes } \\
\hline $\begin{array}{l}\text { Students } \\
\text { Parents } \\
\text { Communities } \\
\text { Teachers' experiences } \\
\text { Food deserts } \\
\text { Dropping out } \\
\text { Jobs } \\
\text { Foster care } \\
\text { Inequality } \\
\text { Teen pregnancy } \\
\text { Violence } \\
\text { Racism } \\
\text { School like prison } \\
\text { Environment }\end{array}$ & $\begin{array}{l}\text { Health disparities knowl- } \\
\text { edge } \\
\text { Causes of health dispar- } \\
\text { ities (race, gender, class, } \\
\text { immigration, refugee } \\
\text { status) } \\
\text { Civic engagement } \\
\text { Health care access } \\
\text { Socioeconomic factors } \\
\text { Voting } \\
\text { Civil rights } \\
\text { Activism } \\
\text { Action }\end{array}$ & $\begin{array}{l}\text { Empowering } \\
\text { Student aspirations } \\
\text { Student fears } \\
\text { Student reaction to } \\
\text { material } \\
\text { Student passion } \\
\text { Student critical con- } \\
\text { sciousness }\end{array}$ & $\begin{array}{l}\text { Activities (that address } \\
\text { health disparities) } \\
\text { Action research } \\
\text { Teachers' self-reported } \\
\text { limitations } \\
\text { Mapping } \\
\text { Math activities } \\
\text { Units/ topics/ curric- } \\
\text { ulum } \\
\text { Assessment (how you } \\
\text { will know if you are } \\
\text { successful) }\end{array}$ & $\begin{array}{l}\text { Professional develop- } \\
\text { ment tools for teaching } \\
\text { health disparities } \\
\text { Pedagogy } \\
\text { Confidence teaching } \\
\text { health disparities } \\
\text { Resources and partners } \\
\text { needed to teach health } \\
\text { disparities } \\
\text { Social capital } \\
\text { Mentors }\end{array}$ \\
\hline
\end{tabular}

Way curriculum, incorporating health disparities into appropriate sections of their curriculum. The diversity of subjects taught reflected the reality of science education - it varied by districts and schools. TSCORE was designed to have broad reach across subject matter within science courses.

Knowledge about students' social context prior to professional development. Prior to the summer health dispar- ities PD, teachers showed awareness of the sociopolitical realities of students' lives, including a reflection on social groups that the students belonged to, access to social networks, and barriers to health care. The teachers also pointed to changing demographic shifts among their students, particularly for new immigrant and refugee students. One teacher said of her school:

\section{"There's a pretty big divide at Wyandotte. I would}


say there's two bubbles at Wyandotte, maybe three, and it has to do with if you have a community to support you. So, there are students whose families went to Wyandotte or Schlagle or whatever. You go out to a track meet or basketball game, their parents know everybody, they know everybody who knows everybody, they have cousins and uncles in every single neighborhood and it's fascinating. And these kids have access to healthcare, they know you can tell by the way they're dressed, they're wearing Nike, instead of, I don't know Salvation Army and things from charities. And that group's mostly African American, but a lot of Hispanic students as well." - Cindy (pseudonyms used for all participants)

Here the teacher was equating access to healthcare with access to other consumer goods, like name-brand shoes. LaVonna, in speaking about the students whose families are refugees, joined the exchange with Cindy:

"Then there's boys that come to school with pink sweaters on them, and they don't even know that's not worn in America. Like somebody gave it to them, and it's warm and they're gonna wear it. They don't know it's a girl's sweater." - LaVonna

"And then there's a smaller third bubble that's very interesting. That's the foster kids. And for us, that's mostly the White kids. And they feel so disenfranchised. They are just in their own world as far as healthcare and things like that. They have a lot more resources such as Medicaid and social services, so they understand the system. They know when I say Medicaid or Medicare, they know how it works, they know all that. But they're moving so much they don't know what to expect." - Cindy

The focus group Cindy and LaVonna were in had a conversation about changing demographics across the schools - an increase in students in English as a Second Language programming. Cindy pointed out the diversity among the Latinx kids - with Mexican students having many more social connections than the newer immigrants from other parts of Central America.

On the stress of immigration issues specifically, a teacher from Wichita said about a trip for HOSA-Future Health Professionals:

"We were traveling to Orlando for a competition, and even with the certifications, you have to have a social or an ID to get on the plane. I have one student who was so nervous, she didn't know if she could get an ID. They wanted her parents there, but she didn't want to bring her parents because she didn't want them to get in trouble. Especially there is this whole new fear, you know, like on Facebook it says "ICE
[Immigration and Customs Enforcement] is at the Quick Trip." The students will alert each other, they will see it on their social media and they will tell all of their friends. I have a student who will ask to get on the phone and call her mom and let her know not to go to the Quick Trip, so it's definitely a concern of our students." - Jonie

Teachers also cited problems with poverty, hunger, lack of sleep, rearing younger siblings, and lack of access to health care, as the many examples of challenges students faced.

\section{Changing definitions and attitudes about health dispar-} ities. Prior to the summer health disparities PD, teachers defined health disparities as access to care driven by socioeconomic differences and health behaviors driven by cultural differences. Teachers agreed on access to care as a key feature of health disparities:

"Access to food, care, [people] don't necessarily have what they need." - Tim

"Difference in availability of health care." - Scott

"Income based, socioeconomics, who gets what healthcare." - Mona

With respect to the teachers' attitudes about what causes health disparities, they pointed to health behaviors driven by cultural differences:

"Some men don't believe in going to the hospital." - Miguel

"Marrying into a Hispanic family, [they] don't go to doctor when sick. Kids get really sick before seeking care." - Tatiana

Presumably Tatiana meant that by "marrying into" a family meant adopting cultural beliefs about healthcare-seeking. Mona added,

"[There] may be a communication gap between people of different ethnicities." - Mona

"Beliefs. Some communities do not believe. [They] substitute resources - if what they have doesn't work, they go to hospitals." - Miguel

Other teachers cited fear about immigration and health care access, or rurality as causes of health disparities. Several teachers also said that students may not realize that disparities exist.

"Kids don't even realize there is a disparity. They think it's just how their family works. It's not until they get into high school, and say 'you go to the doctor for that.'But they don't know why until they get older and have to deal with that themselves and their families. Has to do with socioeconomic status." - Jonie 
"Something that worries me about our students is

that they don't always recognize that this is an issue.

They think this is the way things are." - Cindy

Igor said that as teachers it is their responsibility to present the students with information and opportunities for learning about these issues, including the unpacking of the systemic nature of health disparities.

After the summer health disparities PD, the teachers used the concepts of "change," "action," and "empowerment" when talking about health disparities. Their descriptions of health disparities were less about the context in which their students lived and more about their understanding of the need to move their students toward critical consciousness, community involvement, and ultimately action. The teachers also had some concrete ideas about the research methods and activities that would facilitate this:

"My definition of health disparities, now [after $P D]$, includes all of the issues we can actually prevent or change involving communities here." - Leroy

Leroy said he learned this definition from the PD in a small group session in which a health disparities researcher not only identified the disparities but also leverage points for changing those disparities.

Another teacher also mentioned that interventions need to happen at "higher levels," meaning at the level of institutional structure and not just providing students with resources:

"It's going to have to involve community action. We went and met the Community Health Council and they talked a lot about voter registration and giving the community a voice, taking action, voting, and creating different policies or saying that redlining isn't right and creating groups to advocate for change." - Cindy

Julie pointed out that the same health disparities researcher referenced by Leroy had said:

"[Health disparities] are not just about differences, but differences that are unfair, [and about] justice."-Julie

After the summer health disparities PD, there was a general trend away from focusing on cultural and community beliefs and a movement toward more emphasis on structural determinants of health and social justice.

Perception of impact on students before professional development. Prior to the summer health disparities PD, the teachers expressed excitement over the possibilities for integrating health disparities content into units.

"I think it will be more personal to them. Get them to think about their own families and their own communities. I think that they will be much more engaged in it [the health disparities content]. " - Mona

"The first thing that came to mind when you asked [about student receptiveness to content] is empowerment. I think that as we are teaching them about it, and what can be done, they are coming up with those projects and ways to impact the community, they are focusing on others and how to help others. But they can also then be empowered to help their own situation." - Donna

The teachers felt similarly to the TSCORE team in the design of the programming: content relevant to the students' realities would resonate.

"I think that a lot of times students feel in education, 'When am I ever going to use this? This material feels so far away'. This allows them to personalize it to their real life, and feel they can make a difference." - Lisa

"And for me, earlier today I turned to Lisa and said, I think our kids are going to get really excited about this. Also, it will open their eyes. Like they don't realize that they can have an impact in their own community, and I think they've never thought about it this way before. I think this will really excite them and make them want to go out and make change happen." - Jonie

Plans for integration of health disparities content into units at the end of professional development. Table 5 shows a sample of units developed by teachers during the summer health disparities PD. TSCORE staff also developed three model units to share with teachers, both as examples and as standalones that could be used in the classroom. For teachers, the range of topics covered by units included infant mortality, population health disparities, lead, asthma, nurturing in infants and its impact on the brain and relationships, and the effects of socioeconomic status and job opportunities on health outcomes.

After the summer health disparities PD, teachers had plans for action research strategies to be utilized in the units they developed. The teachers also reflected, after the summer health disparities PD, on building their students' critical consciousness, as an endpoint to learning in the classroom.

"They [ESL students] are going to do the school nutrition aspect and then hopefully they'll come up with an action plan, whether it's to have more ethnic foods that are available in the school, or whether it's a different menu item of choice. I don't know what their ideas will be but hopefully it will be something that they will go to the school board, even go to the district board, or to the community and ask for a change in the 
Table 5. Sample Project-Based Learning Units focused on Health Disparities

\begin{tabular}{|c|c|c|}
\hline Unit & Driving Question & Courses Taught \\
\hline \multicolumn{3}{|l|}{ Units created by TSCORE teachers } \\
\hline We are the change & $\begin{array}{l}\text { How can we improve socio-economic and health outcomes } \\
\text { in our community? }\end{array}$ & Sociology and Economics \\
\hline Clean air project & How does asthma affect the teenage body? & Health Science III \\
\hline Infant mortality & $\begin{array}{l}\text { How do lifestyle and community affect the health of an } \\
\text { unborn child? }\end{array}$ & Human Growth and Development \\
\hline Nurturing and resilience & What do students need to thrive? & Human Growth and Development \\
\hline Chance the researcher & $\begin{array}{l}\text { How can we help the community overcome the probability } \\
\text { of poor health outcomes? }\end{array}$ & Health Science III; Math \\
\hline Leading the way to better water & Is our water safe to drink? & Physical Science; Math \\
\hline $\begin{array}{l}\text { BioMed capstone introduction for Project } \\
\text { Lead the Way }\end{array}$ & How do social determinants of health affect mental health? & Academic Enrichment \\
\hline Project Lead the Way content & How does mental health affect physical health? & BioMed I; BioMed II \\
\hline \multicolumn{3}{|l|}{ Units created by TSCORE staff } \\
\hline Health disparities introduction & $\begin{array}{l}\text { How do various factors (social, environmental, etc.) } \\
\text { influence larger social trends such as health disparities? }\end{array}$ & \\
\hline Health advocacy & $\begin{array}{l}\text { How can we as individuals identify and address the major } \\
\text { health issues in our community? }\end{array}$ & \\
\hline Health careers & What is the place for me in the health care system? & \\
\hline
\end{tabular}

All units and supporting materials available for download at http://www.kumc.edu/t-score-ks.html

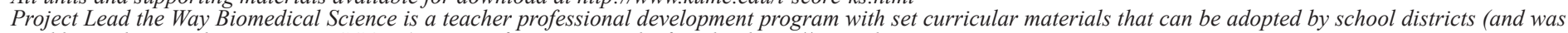
used by Wichita teachers prior to TSCORE). More information can be found at https://www.pltw.org

nutrition value for their food at the schools. So, whether it's the stuff that's offered in the snack shop, whether it's stuff that's offered for breakfast in the classroom, whether it's different menu items that would answer all the different cultural desires or eating habits in lunch as opposed to just those of the "American" ethnic group. So hopefully their action will be first in the school, but then once they've done that, then they will see that 'Hey if I can have change in my school maybe I can also have change in the community'." - LaVonna

LaVonna said that students would conduct the research themselves, collecting data over the breakfast and lunch period, assessing nutritional value of foods. The students would also use ethnographic methods (learned during TSCORE PD) to understand peer food choice. Research activities would culminate in an action plan for the lunch room. While the students use different analysis tools (including quantitative tools, like graphs), they would be empowered to simultaneously give their opinions on the meaning of data and advocate for change. Thus, LaVonna neatly integrated subject matter (math) with content (food and nutrition disparities) and method (action-oriented research) in order to create a meaningful experience for students.
"For my class, I'm really focusing on communication, how the different systems communicate with one another and work together. I was interested in how the communication occurs between medical professionals but also between the medical professionals and the patient. So, one activity to get them thinking about that is that they start with that survey that we saw in the first week [of PD] where they get two different patient backgrounds and they don't know what's different. They don't know what other people have, and they have to say how they would treat that patient. And then we talk about, OK, well what might be different? Why would that be the case? And then they are going to go out and interview a medical professional about how they take histories, and if they ask about mental health. And then go to the community and ask maybe 10 people what their last interaction with their doctor was like. So just trying to get them out and communicating. "-Donna

Scott also had a project in which students got out in the community.

"My class is human body systems and the school is North East Magnet school, so we have kids from all across Wichita attend our school it's not just a com- 
munity school. And so that gives a unique opportunity. What I'm looking at is centered around over-weight and obesity and having the kids go back to their homeschool, home-community area and see what resources are available in their area for physical fitness and healthy activity from looking at parks, to bike trails, to YMCAs. And compare those different parts of Wichita with what's available to show that there's maybe some disparities about where you live in Wichita, as far as what's available to you to combat obesity." - Scott

LaVonna, Donna, and Scott utilized methods for research that would get students out in the community. Most teachers used such an approach. To this end, TSCORE staff developed a model health advocacy unit that two additional teachers adapted for use in the classroom (see Table 5 health advocacy unit and "Chance the Researcher" unit). Igor also developed the "We Are the Change Unit" that got students to assess community needs with a survey and develop an intervention after analyzing survey results. Activities were held at a health and job fair that Igor's class arranged in partnership with community members.

Resources need to be successful. Teachers were aware both before and after the summer health disparities PD that community connections were key to integrating health disparities content in a way that would be meaningful for the students and for their teaching.

Prior to the summer health disparities PD, teachers said:

"Community connections, that's the big thing. Like how can I bring math into what the kids need to know about things into the community? How can they learn what the numbers tell them? Because the numbers are out there on the internet. You can find that stuff, but what is it that I need to show them? That will help them bring that math piece in, to make it relevant to help them learn." - LaVonna

"I definitely think number one is the activism piece. I know that I need that support because I can get the kids so far and then they get frustrated that I can't get them out in the community doing things. I need the connections and the support from the community. The second thing is really mentorship for me. I need the kids to have mentors. Sometimes I get so overwhelmed it's just me doing all this stuff with them. I can only take them so far. Then they get frustrated because I'm not providing them what they need, and I don't know how to help. So, some kind of mentor program or just access to people that can answer their questions when I can't." - Cindy

After the summer health disparities PD, teachers agreed that having an inventory of all the researchers, their special- ties, and information for contacts they've made would help jog their memories about content expertise and availability. These people could be tapped for help with developing lessons, having guest speakers, or as Cindy said, just answering questions. Wichita teachers specifically cited the importance of having contact with the influencers in their communities.

"I hope I can get my kids [contacts with] community members, such as a member of the parks and recreation department in Wichita or some YMCA membership directors, or that type of person who actually can influence and impact their community when the kids come up with the barriers or restrictions in their particular area for physical activity. That way we can actually get the stakeholders involved that can make a difference and the kids can see a change." - Scott

Here Scott articulated that connection between partnerships and making the content truly resonate with the students and their ability to effect change.

Nearly all the teachers, after professional development, cited the social networks associated with TSCORE staff, speakers, resources, and contacts in the community. Leela said it had been empowering to know that they had met so many professionals that were actually willing to be called on as resources. Natalie characterized it in the following way:

"We're here. What do you need? How can we help?

It's like really? Wow." - Natalie

The teachers appreciated access to a network of research and community professionals before the summer health disparities PD. But after the summer health disparities PD, having been exposed to many of these connections, teachers had an actual inventory of networks created through the PD that they could utilize.

\section{DISCUSSION}

The premise of this study and the PD was that if teachers were empowered to integrate health disparities content that resonates with students' realities, then those students would be more engaged and motivated to pursue STEM solutions to local problems. A starting point for the research was to examine teachers' perceptions of using health disparities content to engage high school students in urban communities.

Teacher awareness of students' realities before professional development. A sample of urban high school teachers who elected to participate in a summer health disparities PD described their students' strengths and challenges related to immigration, acculturation, poverty, social networks and social support. This finding indicates some level of sociocultural consciousness (Villegas and Lucas, 2002), even before PD. This suggests that the teachers may be well prepared to bring about changes for their students. 
Knowledge and attitudes about heath disparities after professional development. After completing the summer health disparities PD, teachers' definitions of health disparities reflected a greater awareness of the role of action, activism, and civic engagement as part of health disparities. That is likely reflective of the underlying principles of PD, the weekly content (Table 1), and interaction with researchers who used this language of activism. TSCORE staff also designed a model health advocacy unit in the first year of implementation alongside the first cohort of teachers. Subsequent cohorts of teachers were exposed to this content. It is also possible that the conversations could have been a reflection of the teachers' priorities and sense of what would truly motivate their students.

Units developed during professional development aligned with community engagement and student activism. Indeed, all units developed by teachers included a civic engagement or advocacy component. For example, one of the TSCORE units, "Leading the Way to Better Water," focused on answering the question "Is our water safe to drink?" Prior to analyzing data around lead levels and other contaminants in the water, students conducted a literature review on the impact of water quality from a multiplicity of perspectives including physical health, birth outcomes and student achievement. With new knowledge and results from water tests, they created public service announcements about the linkages between water quality and health disparities in several languages spoken in the community. The unit "Nurture and Resilience" focused on answering the question "What do students need to thrive?" Using ethnographic methods that teachers learned in PD, students were instructed to collect and analyze data on how different cultures in their own community promote resilience in children. Following this, students collected and analyzed survey data to study the school climate - that is, the school's institutional culture - and its effect on student resilience. The results guided a series of recommendations for change that were later presented to the school administration, as well as to members of the school board to promote a climate in which students can thrive.

Perceived impact of health disparities content on students and barriers to successful integration of content. Findings from this study suggest that high school science teachers feel positively toward creating an engaging classroom for students in urban communities when integrating health disparities curricula that reflected the students' lived experiences. The teachers also perceived positive impact on students before professional development, clear plans for integration of health disparities content after professional development, and a realistic acknowledgment of barriers to engaging partners throughout the process of professional de- velopment. Like other long-term studies of teacher-researcher PD (Storm and Lichenstein, 2019), TSCORE teachers built out new social networks with research partners through PD and said those partnerships were critical to ongoing support through the school year to fully integrate health disparities content in the classroom.

\section{Benefits of integrating health disparities content in the} classroom. Although research is scant in this area, there are studies that show the incorporation of health disparities content via similar methods in academic settings, for example among undergraduate, graduate, and medical students, enhances learning among students (Anderson et al., 2011; Florence and Behringer, 2011; Jacquez and Ghantous, 2013; Smith et al., 2007). A 2010 Institute of Medicine report recommends clinical training within community settings compared to health care settings help learners to more "fully understand and appreciate how social contextual factors contribute to disparities through instruction about disparities in community settings" (Cené et al., 2010). TSCORE might facilitate some of these opportunities for high school students.

Given the paucity of health disparity curricula within high school science education, there are robust examples of health disparities curricula within undergraduate and medical education curricula that may be modeled. These curricula have bolstered student and teacher opportunities by integrating learning experiences with patients in community settings for which learners are able to encounter patients from communities who are impacted by health disparities (Chamberlain et al., 2008; Davidson, 2002; Vela et al., 2008). In addition to expanding the students' worldview and exposure to health disparities curricula, there also is opportunity to impact individual health. A recent Robert Wood Johnson report that details the association between health and education among primary and secondary education students cites the benefits of an integrated curricula where an infusion of partners from multiple disciplines (public health, psychology, public policy, social work) is an opportunity to improve the student's health, overall (Lawrence and Thorne, 2016).

Limitations. This study is not without limitations. For one, the sample is small, so results are not necessarily generalizable. Yet the results are transferrable to others that are working in the urban high school education space to develop innovative content that could excite and ignite the imaginations of students, given rapidly changing demographics of high school students. The methodology of the study - preand post-PD - is also limited in its ability to generate conclusions about the effectiveness of the PD. Future and ongoing evaluation efforts, including classroom/teaching observations and surveys with students about their experience with content, will create a more holistic picture. Nevertheless, 
this study sheds light on the group of adults responsible for delivering education - including their perceptions, biases, attitudes, and intentions to deliver health disparities content. As a baseline, this information can inform other readiness and implementation efforts, prior to delivery of health disparities PD.

\section{CONCLUSION}

So, what can be learned from this study? 1) This sample of teachers showed awareness of the social challenges students face, even prior to starting a summer PD on health disparities; 2) TSCORE teachers appreciated the role of community engagement and activism as a solution to health disparities and felt that they would be able to engage students with this material; 3) Teachers need resources, mostly in the form of community connections, to fully integrate health disparities lessons, with community engagement infused throughout. For this, they felt the partnerships with the university offering the PD and TSCORE staff could help leverage social networks and facilitate access to community partners. These lessons can be integrated into teacher PD, and future efforts should assess impact of these efforts on students.

\section{AUTHOR INFORMATION Corresponding Author}

Megha Ramaswamy. Preventive Medicine and Public Health, University of Kansas School of Medicine. 3901 Rainbow Boulevard, MS 1008. Kansas City, Kansas 66160. Tel 913-588-1053.mramaswamy@kumc.edu

\section{Author Contributions}

The manuscript was written through contributions of all authors. All authors have given approval to the final version of the manuscript.

\section{FUNDING SOURCES}

The authors would like to acknowledge funding from the National Institute of General Medical Sciences for a National Institutes of Health Science Education Partnership Award (SEPA) under Award Number R25GM129226 (current CoPIs, Ramaswamy and Chang; original PI, Cupertino).

\section{ACKNOWLEDGMENTS}

The authors would like the acknowledge Mackenzie Koester, Maggie Cearley, and Joi Wickliffe for their assistance in administering focus groups and managing data.

\section{ABBREVIATIONS}

ESL: English as a Second Language; ICE: Immigration and Customs Enforcement; PD: Professional Development; STEM: Science, Technology, Engineering, Math; TSCORE: Teachers and Students for Community-Oriented Research and Education

\section{REFERENCES}

Alonso Luaces, M., Cearley, M., Chang, K., Cupertino, P., and Ramaswamy, M. (2018). Envisioning career technical education as a platform for student empowerment. CTE Journal, 6(2), 1-13.

Anderson, L.S., Royster, M.O., Bailey, N., and Reed, K. (2011). Integrating service-learning into an MPH curriculum for future public health practitioners: strengthening community-campus partnerships. Journal of Public Health Management and Practice, 17(4), 324-327.

Cené, C.W., Peek, M.E., Jacobs, E., and Horowitz, C.R. (2010). Community-based teaching about health disparities: Combining education, scholarship, and community service. Journal of General Internal Medicine, 25(Suppl 2), 130.

Chamberlain, L.J., Wang, N.E., Ho, E.T., Banchoff, A.W., Braddock, C.H., and Gesundheit, N. (2008). Integrating collaborative population health projects into a medical student curriculum at Stanford. Academic Medicine, 83(4), $338-344$.

Davidson, R.A. (2002). Community-based education and problem solving: the Community Health Scholars Program at the University of Florida. Teaching and Learning in Medicine, 14(3), 178-181.

Florence, J. and Behringer, B. (2011). Community as classroom: teaching and learning public health in rural Appalachia. Journal of Public Health Management and Practice, 17(4), 316-323.

Jacquez, F. and Ghantous, S. (2013). Community-partnered needs assessment: a strategy to teach college students about health disparities. Journal of Prevention and Intervention in the Community, 41(2), 68-74.

Kansas State Department of Education. (2019). Kansas Science Standards. Available at: https://community.ksde.org/Default.aspx?tabid $=5918$

Krajcik, J. (2015). Three-dimensional instruction. The Science Teacher, 82(8): 50.

Krajcik, J., Codere, S., Dahsah, C., Bayer, R., and Mun, K. (2014). Planning instruction to meet the intent of the Next Generation Science Standards. Journal of Science Teacher Education, 25(2), 157-175.

Lawrence, J. and Thorne, E. (2016). A Systems Approach to Integrating Health in Education. Robert Wood Johnson Foundation Discussion Paper available at: https://www. rwjf.org/en/library/research/2016/09/a-systems-approach-to-integrating-health-in-education.html 
National Research Council. (2015). Guide to implementing the next generation science standards. National Academies Press.

National Research Council. (2013). Next generation science standards: For states, by states.

Nutbeam, D. (2000). Health literacy as a public health goal: a challenge for contemporary health education and communication strategies into the 21 st century. Health Promotion International, 15(3), 259-267.

Siciliano, P, Hornbeck, B., Hanks, S., Kuhn, S., Zbehlik, A., and Chester, A.L. (2018). Taking a look at the Heath Sciences and Technology Academy (HSTA): Student-research partnership increases survey size, hands-on STEM learning, and research-community connections. Journal of STEM Outreach, 1, 1-3.

Smith, W.R., Betancourt, J.R., Wynia, M.K., Bussey-Jones, J., Stone, V.E., Phillips. C.O., Fernandez, A., Jacobs, E., and Bowles, J. (2007). Recommendations for teaching about racial and ethnic disparities in health and health care. Annals of Internal Medicine, 147, 654-665.

Southern Poverty Law Center. (2019). Teaching Tolerance: Lesson Analyzing Health Disparities. Available at: https:// www.tolerance.org/classroom-resources/tolerance-lessons/analyzing-health-disparities

Sprague Martinez, L.S., Bowers, E., Reich, A.J., Ndulue, U.J., Le, A., and Peréa, F. C. (2016). Engaging youth of color in applied science education and public health promotion. International Journal of Science Education, 38(4), 688-699.

University of Maryland Health Sciences and Human Services Library. (2019). Project SHARE. Available at: http://guides. hshsl.umaryland.edu/c.php?g=76220\&p=1538472

Vela, M.B., Kim, K.E., Tang, H., and Chin, M.H. (2008). Innovative health care disparities curriculum for incoming medical students. Journal of General Internal Medicine, 23 (7), 1028-1032. 